\title{
PENINJAUAN ASPEK AKSES DAN KEAMANAN PEJALAN KAKI PADA PEDESTRIAN DALAM OPTIMALISASI FUNGSI RUANG TERBUKA HIJAU IMAM BONJOL PADANG
}

\author{
Oleh: Friyessi.ST.MT \\ Jurusan Arsitektur Fakultas Teknik dan Perencanaan \\ Universitas Eka sakti \\ Email :freevessi21@gmail.com
}

Ringkasan

Sebagai kota yang rawan gempa kota Padang selalu melakukan antisipasi dan mitigasi agar dapat memperkecil korban yang ditimbulkan dari bencana tersebut. Selain menampung berbagai kegiatan Ruang terbuka Imam bonjol dapat dijadikan sebagai tempat berkumpul atau lokasi evakuasi sementara akibat gempa yang dapat terjadi kapan saja bagi masyarakat disekitar pasar raya Padang. Agar RTH Imam bonjol dapat berfungsi maksimal harus memperhatikan akses yang cepat dan aman serta jalur pejalan kaki yang bebas hambatan supaya dapat berjalan bahkan berlari menuju ruang terbuka dalam upaya penyelamatan diri. Penelitian ini bertujuan untuk mengetahui sejauh mana lapangan Imam Bonjol siap menjadi lokasi evakuasi ditinjau dari akses maupun kelengkapan jalur pejalan kaki menuju Ruang terbuka Hijau Imam bonjol di Padang.Data didapat dari literatur dan survey kelokasi langsung berupa ekplorasi kegiatan maupun kondisi sarana pejalan kaki dengan berpedoman pada standar kenyamanan bagi pejalan kaki baik untuk beraktifitas sehari hari maupun dalam situasi darurat saat gempa. Hubungan ruang terbuka dengan area parkir yang aman bagi kendaraan merupakan penunjang yang akan dapat memaksimalkan fungsi dari ruang terbuka tersebut.Penelitian ini dapat dijadikan sebagai guide line dalam upaya perbaikan dalam upaya mengoptimalkan fungsi Ruang terbuka hijau Imam bonjol padang.

Kata kunci : Ruang terbuka hijau, pedestrian, gempa 


\title{
PEDESTRIAN PATH REVIED FROM ACCESS ASPECT AND SAFETY TO PEDESTRIAN IN OPTIMIZATION FUNCTION GREEN OPEN SPACE IMAM BONJOL PADANG.
}

\begin{abstract}
As an earthquake-prone city, the city of Padang always carries out anticipation and mitigation in order to minimize the casualties caused by the disaster. In addition to accommodating a variety of activities, Imam Bonjol's open space can be used as a gathering place or temporary evacuation site due to the earthquake that can occur at any time for the community around the Padang main market. In order for Imam Bonjol to function optimally, he must pay attention to fast and safe access and pedestrian paths free of obstacles to be able to walk and even run into open space in an effort to save yourself.

This study aims to determine the extent to which the Imam Bonjol field is ready to become an evacuation site in terms of access and completeness of the pedestrian path to the Imam Bonjol Green Open Space in Padang. Data is obtained from literature and direct location surveys in the form of exploration of activities and conditions of pedestrian facilities guided by comfort standards for pedestrians both for daily activities and in emergency situations when an earthquake. The relationship between open space and parking area that is safe for vehicles is a support that will be able to maximize the function of the open space.
\end{abstract}

Keywords: Green open space, pedestrian, earthquake 


\section{PENDAHULUAN}

\section{Latar Belakang}

Pada saat ini kota Padang sedang giat giatnya membangun, dengan kecendrungan perencanaan pada sektor komersil yang jelas bernilai ekonomis. Salah satunya membangun Mall seperti Trans Mall yang sudah ramai dikunjungi oleh masyarakat.Selain Mall atau pusat perbelanjaan dan tempat bermain dengan teknologi tinggi juga tempat hiburan mewah lainnya yang hanya dapat diakses oleh kalangan atas yang menyebabkan adanya kesenjangan yang amat besar antara golongan yang diuntungkan (the privileged) dan Golongan yang dirugikan (the deprived).Padahal banyak sekali rekreasi murah yang dapat diperuntukan untuk umum seperti sepanjang sungai berupa jogging track dibawah pepohonan hijau atau,tempat makan minum ditepi jalan yang ditata rapi,pedestrian yang asri,atau bahkan rekreasi ditaman taman kota, seperti pada Ruang Terbuka Hijau Imam Bonjol Padang.

Berangkat dari Issue tentang pindahnya pusat pemerintahan kota Padang ke air pacah dan akan menata kembali kawasan imam bonjol sebagai Ruang umum kota maka perlu adanya suatu penelitian tentang keberadaan RTH Imam Bonjol, apakah fungsi dan kontribusinya terhadap kota sudah maksimal baik sebagai fungsi utama maupun tambahan.

\section{Existing kawasan}
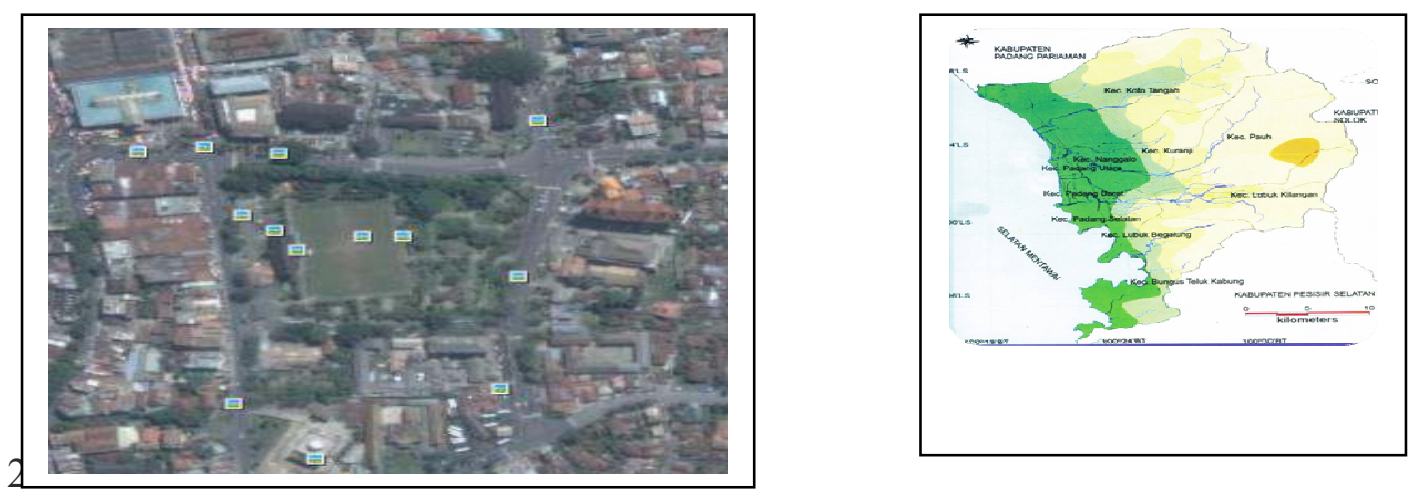

Saat ini RTH Imam Bonjol adalah salah satu ruang terbuka Kota Padang yang semakin meningkat jumlah kegiatannya. Mulai dari mereka yang berekreasi bersama keluarga, bermain di taman dan games indoor, olahraga sepak bola dan bola volly, hingga ajang event organizer yang sering diadakan di halaman depan RTH maupun dilapangan sepak bola.

RTH Imam Bonjol berada berdekatan dengan pusat kota, terutama Pasar Raya, yang berimbas sebagai penempatan sementara pedagang pasar raya pada saat renovasi pasar inpres yang roboh akibat gempa 30 September 2009. 

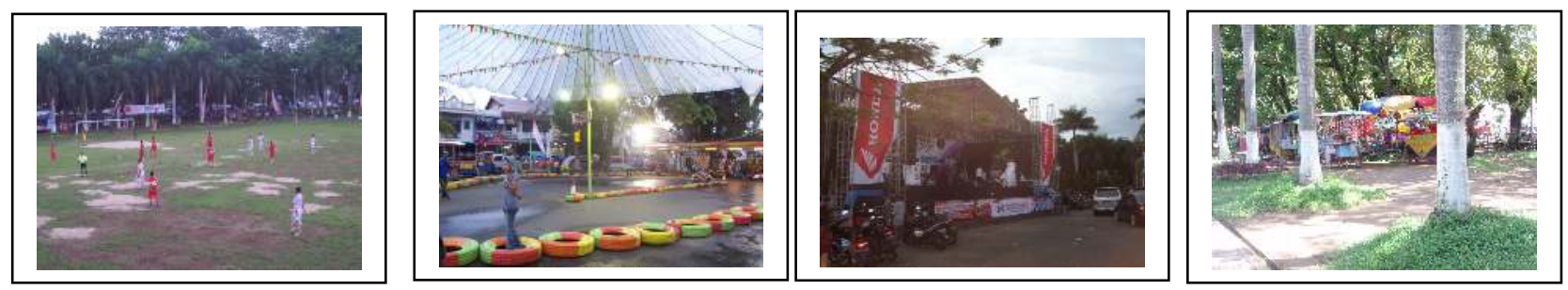

Suasana dankegiatan pada RTH Imam Bonjol Padang

Pada tanggal 30 september 2009 merupakan gempa bumi terbesar dikota Padang yang terjadi 2 kali dengan kekuatan 7,6 skala richter dengan pusat gempa di Pariaman (00,84 LS 99,65 BT) pada kedalaman $71 \mathrm{~km}$. Berdasarkan laporan diketahui bahwa gempa pertama begitu kuat terasa di seluruh Sumatra Barat,terutama di daerah pesisir pantai (http:/earthquake.usgs.gov,earthquake/eqinthenews). Belajar dari sejarah maka seharusnya kita berpedoman kepada semua yang telah terjadi di kota Padang dengan memberikan akses dan jalur bagi masyarakat disaat darurat gempa dalam usaha menuju titik kumpul atau penyelamatan sementara.

Sebagai kota yang rawan gempa kota Padang selalu melakukan antisipasi dan mitigasi agar dapat memperkecil korban yang ditimbulkan dari bencana tersebut. Dalam konteks mitigasi bencana, penentuan titik kumpul merupakan rencana tanggap darurat yang penting dalam kesiapsiagaan sebagai usaha penyelamatan. Selain menampung berbagai kegiatan/aktifitas umum ,Ruang Terbuka Hijau Imam bonjol diharapkan juga bisa menjadi titik kumpul atau lokasi evakuasi sementara pada saat gempa yang sering terjadi dikota Padang terutama bagi masyarakat disekitar Imam Bonjol dan masyarakat yang beraktifitas dipasar raya Padang.
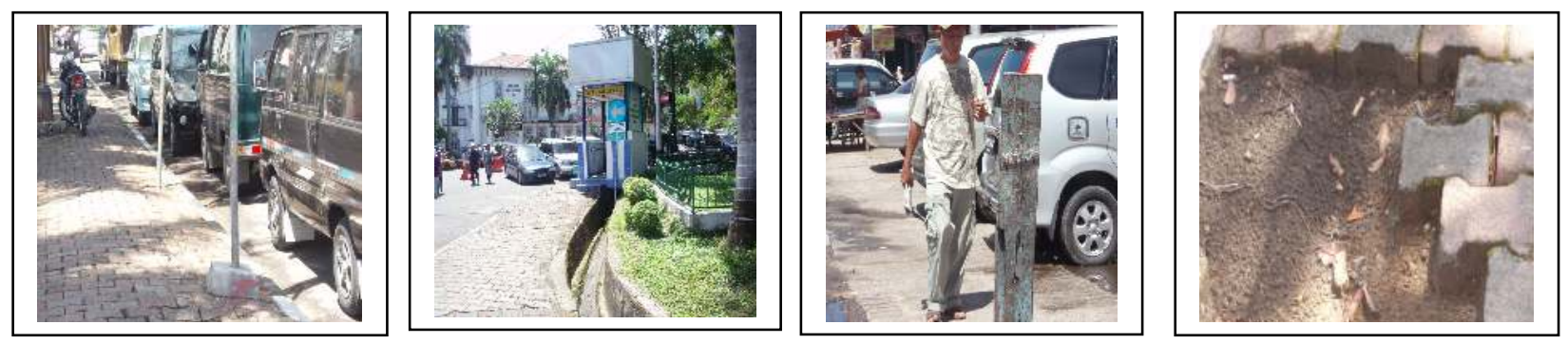

Kondisi dan situasi Pedestrian pada kawasan RTH Imam Bonjol

Adanya hubungan ruang terbuka dengan area parkir yang aman bagi kendaraan merupakan penunjang yang akan dapat memaksimalkan fungsi dari ruang sebagai titik kumpul.Penelitian ini dapat dijadikan sebagai guide line dalam upaya perbaikan sarana pejalan kaki agar fungsi dari RTH Imam bonjol dapat lebih optimal sebagai lokasi titik kumpul serta fungsi evakuasi sementara disaat gempa bumi di kota Padang. 


\section{Pembatasan Masalah}

Berdasarkan identifikasi dari permasalahan maka penelitian ini akan melihat dan meneliti dari aspek akses menuju RTH Imam Bonjol serta keamanan pejalan kaki pada pedestrian disekitar kawasan Imam bonjol dengan memfokuskan pada saat terjadi gempa, agar proses penyelamatan menjadi lebih aman dan lancar. Bagaimana Pedestrian dapat berintegrasi dengan Ruang terbuka dalam upaya optimalisasi Ruang terbuka hijau Imam Bonjol sebagai lokasi evakuasi sementara selain fungsi ekologis dan fungsi ruang terbuka umum kota.

\section{Perumusan Masalah}

Sebagai tempat berkumpul atau lokasi evakuasi sementara akibat gempa yang dapat terjadi kapan saja bagi masyarakat disekitar RTH Imam bonjol dan pasar raya Padang perlu mempersiapkan sarana pejalan kaki dan akses menuju RTH Imam Bonjol agar dapat berfungsi maksimal dan aman disaat kondisi darurat gempa,untuk itu perlu diketahui :

- Bagaimana kondisi Pedestrian atau jalur pejalan kaki apakah aman dan bebas dari segala hambatan dan rintangan supaya dapat berjalan bahkan berlari menuju ruang terbuka dalam upaya penyelamatan diri.

- Bagaimana akses yang lancar dan mudah menuju Ruang terbuka Imam Bonjol agar dapat memfasilitasi situasi darurat yang cepat dan singkat. .

\section{Tujuan Penelitian}

Penelitian ini bertujuan untuk mengetahui hubungan antara Ruang terbuka dengan pedestrian dan secara simultan terhadap akses bagi pejalan kaki dalam berintegrasi pada ruang terbuka kota .Bagaimana mengoptimalkan fungsi Ruang terbuka Hijau Imam Bonjol selain dari fungsi utama ekologis, juga mempunyai fungsi penampungan/ perlindungan sementara disaat terjadi gempa bumi khususnya untuk masyarakat disekitar kawasan Imam Bonjol dan pasar raya Padang.

\section{Manfaat Penelitian}

Penelitian ini diharapkan dapat bermanfaat sebagai berikut:

1. Sebagai gambaran kondisi awal untuk mengetahui kondisi dan kegiatan yang ada pada RTH agar dapat menyesuaikan dengan fungsi sebagai titik kumpul /evakuasi sementara pada saat gempa.

2. Perbaikan kondisi Pedestrian ditinjau dari aspek akses dan keamanan pejalan kaki baik disaat biasa maupun dalam keadaan darurat terjadi gempa. 


\section{TINJAUAN PUSTAKA}

\subsection{Urban Design}

Delapan elemen Perancangan Kota menurut Hamid Shirvani (1986):

1. Tata Guna Lahan (Land Use)

2. Bentuk dan Massa Bangunan

3. Sirkulasi dan ruang Parkir

4. Ruang Terbuka

5. Jalur Pedestrian

6. Kegiatan Pendukung

7. Tanda tanda

8. Preservasi dan Konservasi

\subsubsection{Ruang terbuka}

Ruang terbuka, adalah ruang-ruang dalam kota atau wilayah yang lebih luas baik dalam bentuk area/kawasan maupun dalam bentuk area memanjang/jalur dimana dalam penggunaannya lebih bersifat terbuka yang pada dasarnya tanpa bangunan. Ruang terbuka terdiri atas ruang terbuka hijau dan ruang terbuka non hijau. Ruang Terbuka Hijau (RTH), adalah area memanjang/jalur dan atau mengelompok, yang penggunaannya lebih bersifat terbuka atau umum dengan fungsi utama sebagai paru paru kota,ekologis dan fungsi tambahan sebagai fasilitas social dan cermiman budaya setempat.Ruang terbuka non hijau, adalah ruang terbuka di wilayah perkotaan yang tidak termasuk dalam kategori RTH seperti Pedestrian .

Penelitian ini diterapkan untuk mengoptimalkan fungsi dari RTH tersebut sebagai ruang terbuka umum kota dan sebagai titik kumpul yang diidentifikasikan untuk mempermudah proses evakuasi atau penyelamatan diri sebagai usaha meminimalkan korban jiwa saat terjadi bencana gempa bumi.

Sebuah ruang publik sangat dipengaruhi oleh ekpressi dari elemen elemen dan unsur unsur pembentuk ruang publik serta respon dari pemakainya yang dapat menghadirkan Atmosphere (suasana) pada suatu kawasan.Respon ini ditentukan oleh peran intelektual dan emosi pemakainya yang langsung maupun tidak langsung dipengaruhi oleh tingkat pendidikan,latar belakang nilai nilai yang dianut,pengalaman, dan faktor sosial budayanya. 
Fenomena ini menegaskan bahwa dalam arsitektur kawasan binaan diharapkan terdapat hubungan yang harmonis dan memiliki derajad kesesuaian yang tinggi antara prilaku manusia dengan kawasan ruang public.

Dalam suatu penelitian diketahui dua gambaran Prilaku manusia diantaranya:

\section{Prilaku Normal}

Dalam keadaan normal orang cenderung mencari jalan yang terpendek dengan cara termudah dan menghidari jalan memutar.

Artinya orang berusaha mencapai tujuannya secepat mungkin guna menghemat energy.Semua orang memiliki zona kenyamanan pribadi dengan menghindari kerumunan

\section{Prilaku Panik}

Pada situasi ini orang cenderung ingin secepatnya mencari penyelamatan dengan berdorongan atau interaksi fisik lainnya,kemungkinan terluka/cedera atau bahkan mati ,karena kekuatan yang dihasilkan mencapai 4500 ton /meter yang cukup untuk meruntuhkan dinding batu bata. Orang yang tersandung dan jatuh akan memperlambat evakuasi

Dapat disimpulkan orang dalam keadaan bencana dan panic mereka kehilangan kemampuan untuk bertindak logis dan mempercayai diri mereka sendiri karena kurangnya kemandirian yang cenderung mengikuti orang lain yang dianggap dapat menyelamatkan mereka .(Jurnal JohannesStroehle 19 Desember 2008, University of Illinois di Urbana-Champaign ). Hal ini dapat diantisipasi dengan mempersiapkan Jalur pedestrian yang bebas hambatan serta bebas bergerak menuju suatu area yang menjadi titik kumpul sementara ketika suasana panic menghadapi bencana.

\subsection{2..Pengertian Pedestrian.}

Pedestrian area merupakan jalur jalan khusus tempat orang dapat berjalan kaki tanpa menggunakan kendaraan, yang terletak disisi jalan baik, yang direncanakan maupun terbentuk dengan sendirinya dan yang menghubungkan satu tempat dengan tempat lainnya. Jalur pedestrian dapat berupa: Trotoar, pavement, Pathway, Plaza, Mall, Zebracross, jembatan Penyebrangan (Danishworo).

\section{A.Persyaratan permukaan trotoar}

-Permukaan trotoar tidak licin,bertesktur datar , sehingga memberi kenyamanan bagi penyandang cacad.dengan kemiringan 1'-0', 
-Diberi ramp agar dapat dipakai oleh pemakai kursi roda.diberi bahan anti peleset alamiah atau buatan.

-Kemiringan ramp 7 sampai 17 \%,dengan lebar 5'-0' dan tinggi tepi jalan 6",

-Lebar trotoar untuk jalan dua jalur min 4'-5' dengan menyediakan tempat istirahat diluar trotoar (Time saver,Site Planning,dan satu jalur 4'

\subsubsection{Titik kumpul}

Dalam usaha menguarangi bahaya dalam kondisi panic pada situasi darurat bencana, masyarakat diarahkan menuju suatu titil kumpul yaitu tempat penyelamatan sementara berupa area yang dapat dicapai dalam waktu singkat dan aman dari segala arah. Untuk itu suatu ruang terbuka dapat difungsikan sebagai tempat berkumpul sebagai lokasi evakuasi sementara sebelum adanya penyelamatan Akhir.

\section{A.Indikator/prasyarat Titik Kumpul adalah:}

-Ketersediaan areal/ruang terbuka yang cukup memadai.

-Mudah diakses oleh korban bencana maupun penolong

-Cukup terlindung dari jangkauan bahaya langsung atau tidaklangsung dari bencana

-Ketersediaan tempat naungan/ruang sementara terutama bagi kelompok rentan (lansia, bayi, ibu hamil, difable)

-Adanya kemudahan akses mobilisasi(perpindahan kelokasi yang lebih aman) secara cepat.

-Ketersediaan sarana komunikasi memadai yang terhubungan dengan struktur organisasi kedaruratan.

-Ketersediaan sarana pertolongan pertama (emergency kits)

-Ketersediaan akses transportasi memadai (mobilisasi transportasi) yang akan membawa ke tempat yang lebih aman secara cepat dan aman.

-Ketersediaan peta jalur evakuasi yang mudah dibaca dan dipahami secara cepat

Berdasarkan indicator/prasyarat titik kumpul maka Ruang terbuka hijau Imam Bonjol dapat digolongkan sebagai area yang bisa digunakan untuk penyelamatan sementara. 


\subsection{Kajian Riset sebelumnya.}

Penelitian sejenis yang pernah dilakukan diantaranya:

1. Stroehle Johanes,desember 19 th 2008,How do pedestrian crowds react when they are in an emergency situation- models and software,University of Illinois at Urbana- Champaign. ( jurnal).

2. Jalur pedestrian dikawasan Perdagangan dan jasa ditinjau dari aksesbilitas dan kenyamanan pengguna,dengan Studi kasus jalan Sudirman kota Salatiga pada tahun 2003 (Rahadi Fitra Anindya, 2003).

3. Identifikasi dan model ruang terbuka hijau sebagai ruang evakuasi bencana alam gempa bumi berbasis SIG di kawasan Sanur, Denpasar, Bali

4. Penentuan tempat evakuasi sementara (TES) dan tempat evakuasi akhir (TEA) untuk gempa bumi dan tsunami dengan pendekatan sistim imformasi geografis,kota Pariaman propinsi Sumatra barat.

\section{METODOLOGI PENELITIAN}

\subsection{Metode dan Disain Penelitian}

Penelitian ini adalah penelitian Survey yang dilakukan untuk mengambil suatu generalisasi dari pengamatan yang tidak mendalam, tetapi generalisasi yang dilakukan bisa lebih akurat bila digunakan sampel yang representative (Riduwan, 2004). Data yang dipakai dalam penelitian ini berupa data primer dan data sekunder. Data primer berupa data yang sudah ada yang didapat dari internet maupun dari instansi terkait,berupa peta atau foto udara . Sementara data sekunder adalah data yang didapat dilapangan, berupa observasi, foto foto situasi dan kondisi lokasi study, wawancara singkat dengan pejalan kaki dan masyarakat disekitar kawasan Imam Bonjol.

\subsubsection{Observasi Lapangan}

Dalam usaha mendata kondisi pedestrian dan akses yang ada menuju ruang terbuka hijau Imam Bonjol Padang dilaksanakan pagi hari dan siang hari. Kondisi fisik yang ada direkam untuk kemudian di interpretasikan dalam bentuk proses analisis dan didukung oleh teori teori. Pemahaman atas kondisi lingkungan yang ada diperoleh melalui rekaman berupa peta, photo, dan gambar gambar pendukung yang dipakai sebagai data dan alat analisa lingkungan .

Observasi lapangan berupa pengamatan tentang

- Kondisi fisik pada pedestrian/trotoar 
- Akses yang ada dari pedestrian (trotoar) menuju RTH Imam Bonjol

Kondisi non fisik melalui teknik wawancara, pengamatan secara berkala, peta, gambaran aktifitas, photo dan lain lain

\section{HASIL DAN PEMBAHASAN}

\subsection{Gambaran Umum Kawasan}

Kota Padang adalah salah satu kota tertua di Pantai Barat,dengan wilayah administrative yang terbagi dalam 11 kecamatan dan 104 kelurahan. Kawasan Ruang terbuka Imam Bonjol terletak di kecamatan Padang Barat. Kota Padang merupakan Ibukota dari propinsi Sumatra Barat dengan luas 694,96 km2 yang dibatasi laut dan pegunungan dengan ketinggian 1.853 mdpl . Berdasarkan data BPS 2017 mempunyai penduduk serta 927.168.jiwa

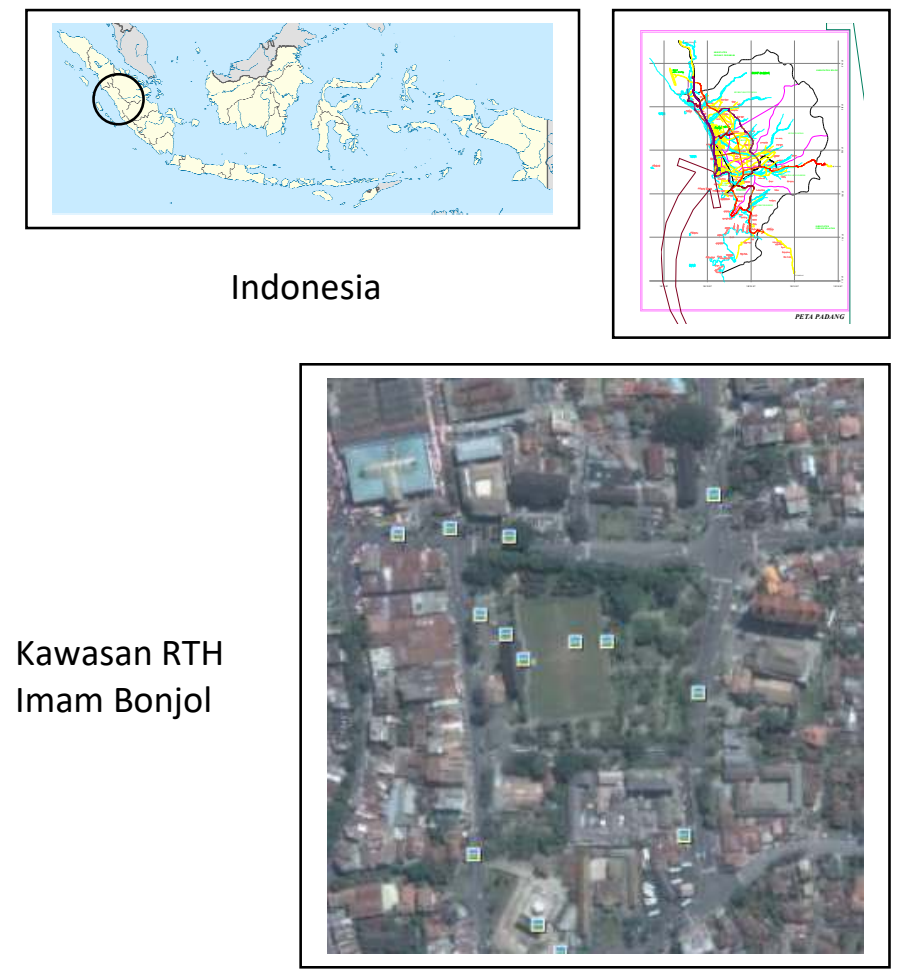

\subsubsection{Kawasan Penelitian.}

Kawasan Imam bonjol merupakan ruang terbuka umum kota Padang yang cukup dikenal karena terletak dipusat kota Padang dan sering digunakan untuk berbagai kegiatan umum,selain fungsi utamanya sebagai paru paru kota. Kawasan ini berbatasan dengan : 
- SebelahTimur berbatasan dengan jalan Bagindo azizchan, sebelah

-Sebelah Utara berbatasan dengan jalan M.Yamin.

-Sebelah Barat berbatasan dengan Jalan Imam Bonjol.

- Sebelah Selatan berbatasan dengan jalan Hasanudin

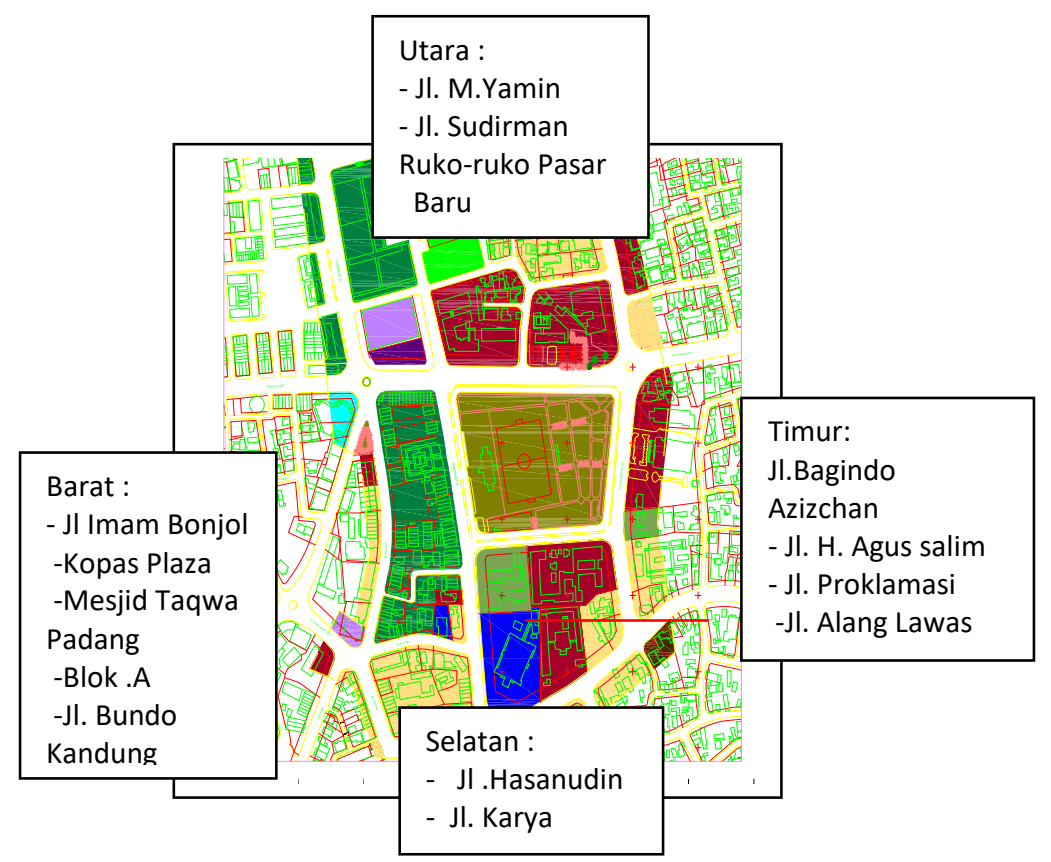

\subsection{Keamanan pejalan kaki}

Keamanan dalam hal ini adalah keadaan lingkungan dan kondisi trotoar yang sangat penting karena dapat menghambat proses penyelamatan diri pada situasi darurat dan kondisi panic. Pada situasi ini orang cenderung akan mencari penyelamatan secepatnya. Keamanan pada saat menyelamtakan diri maupun terhadap kekuatan konstruksi dari elemen trotoar, tata letak elemen, bentuk elemen, dan kejelasan fungsi sesuai dengan persyaratan trotoar ,sehingga dapat dipastikan tidak ada halangan dan rintangan baik bagi pejalan kaki normal dan difable.Selain itu juga dapat meminimalkan keberadaan pedagang kaki lima yang akan memperlambat pergerakan..

\subsection{Analisa Pedestrian.}

Disekitar kawasan Ruang terbuka Imam bonjol merupakan pertokoan,kantor ,dan masjid,serta pasar.Artinya kawasan ini sangat ramai dan padat oleh orang yang berbelanja ataupun bagi yang mempunyai keperluan pada kantor kantor yang ada disekitar kawasan. Bagi yang tidak ada keperluan sebagian ada yang hanya lewat saja, atau mampir pada RTH Imam bonjol beristirahat sejenak, bertemu teman atau sekedar menikmati suasana. 


\subsubsection{Kondisi Trotoar}

Ruang terbuka Imam bonjol berada ditengah pertokoan dan perkantoran yang mempunyai trotoar dikedua sisinya serta dilengkapi bahu jalan badan jalan, dan saluran drainage. Trotoar merupakan sarana pejalan kaki yang utama dan yang paling banyak digunakan.Dengan kondisi yang padat tersebut menjadikan kawasan disekitar RTH Imam Bonjol sebagai kawasan yang selalu aktif sepanjang hari dari pagi hingga malam hari.

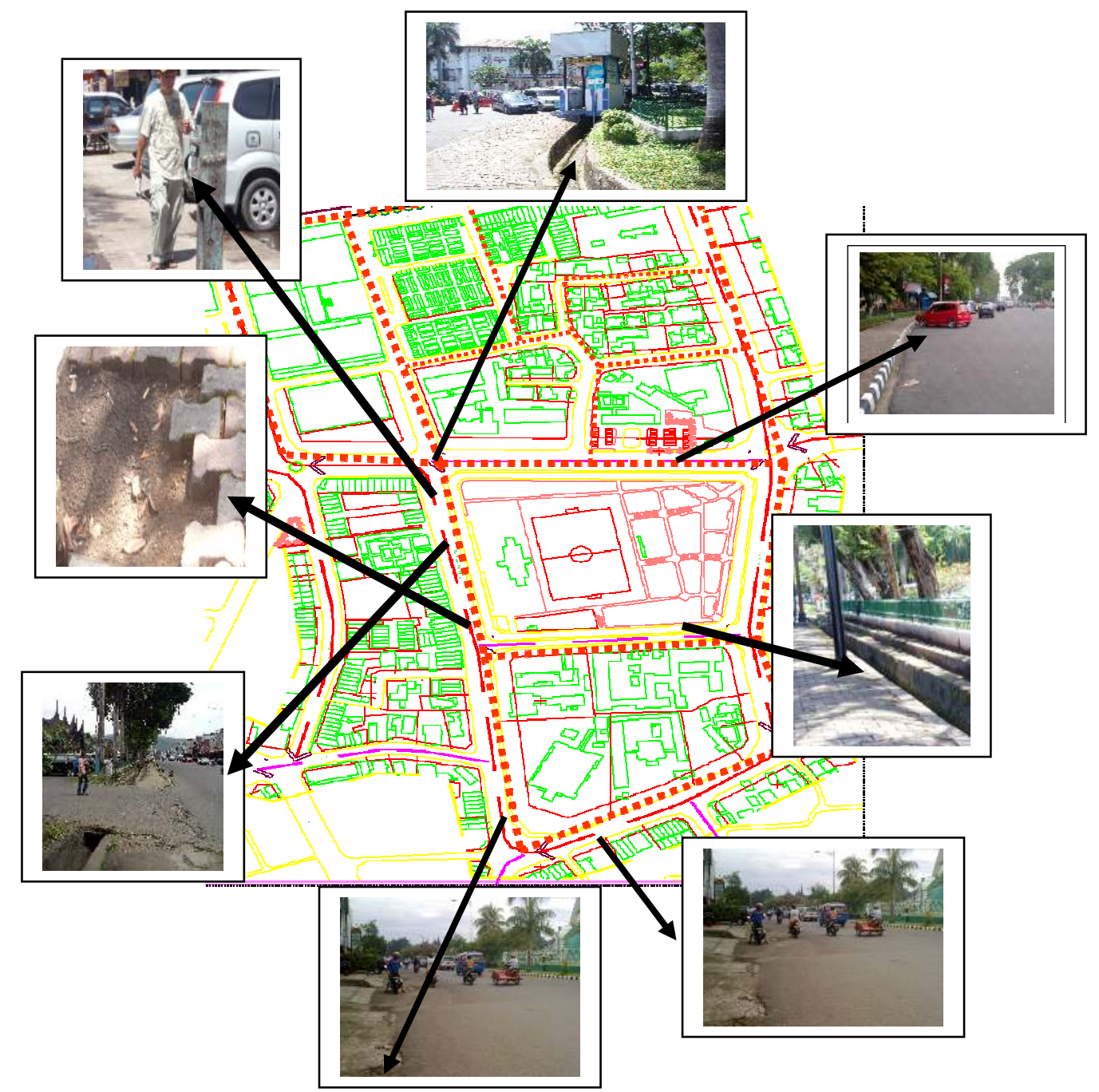

Kondisi Trotoar 


\subsubsection{Kondisi Ruang terbuka Imambonjol.}

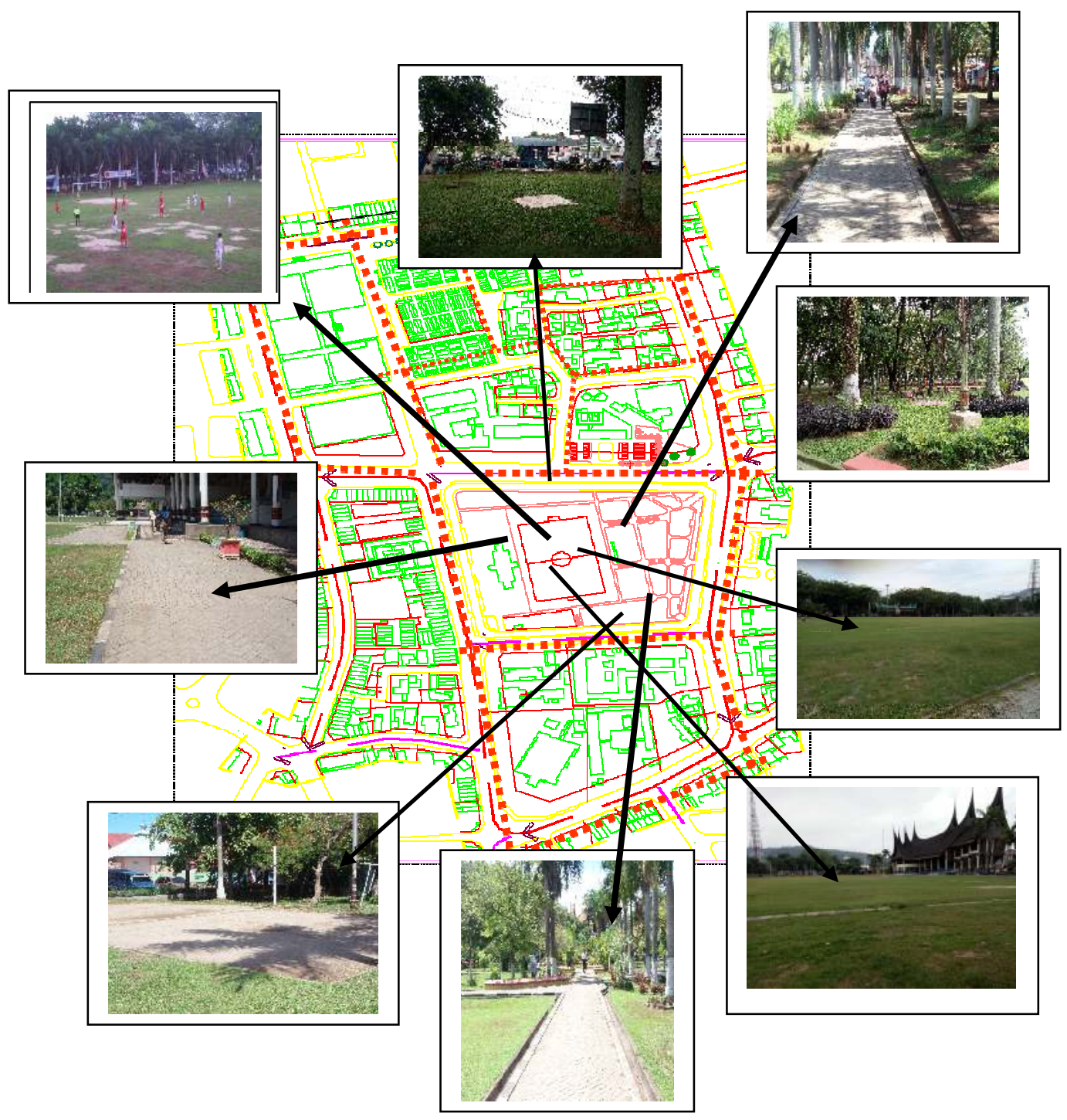




\subsubsection{Akses masuk dan Parkir di Ruang terbuka Imam Bonjol.}

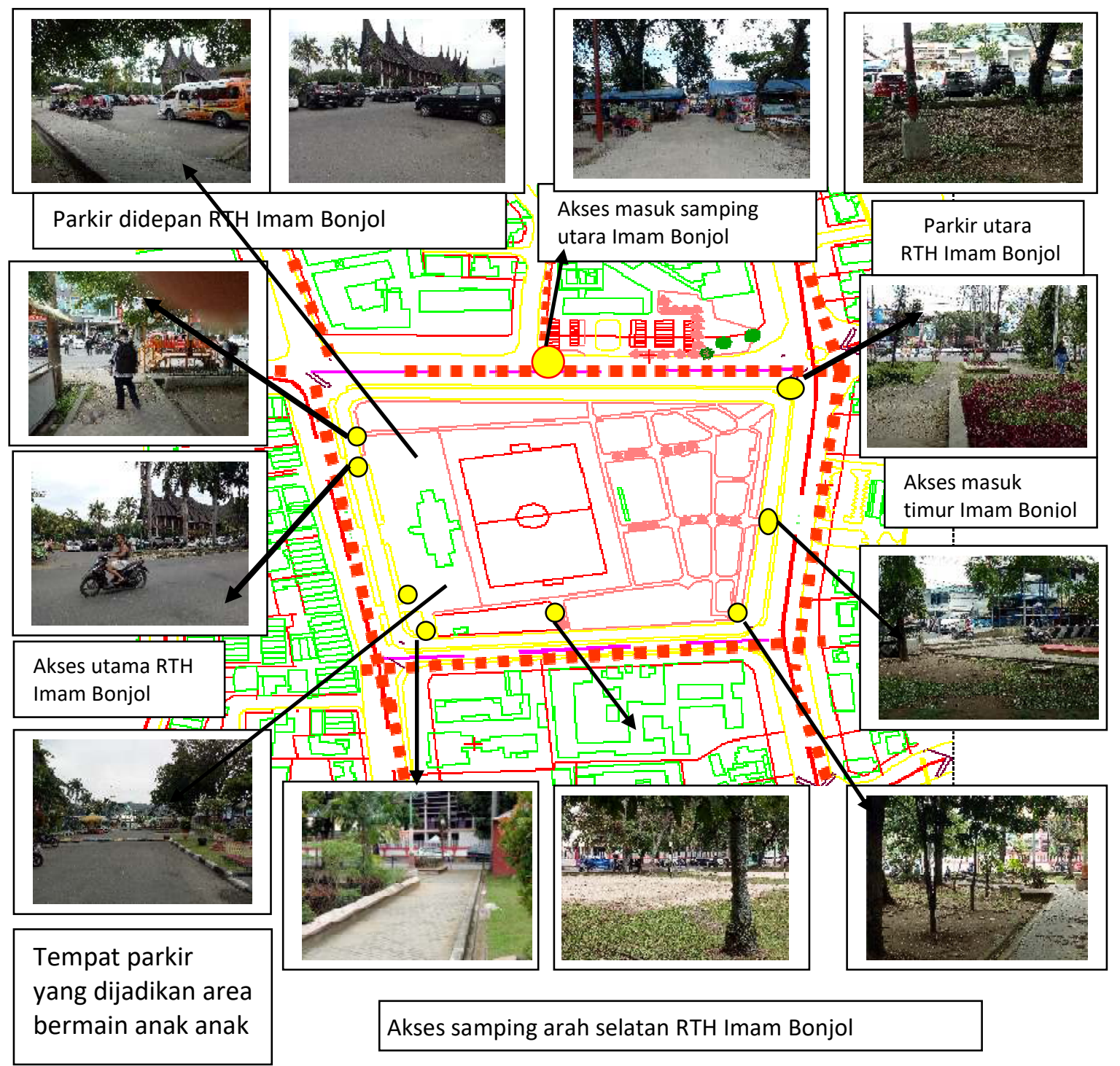

\section{V.Kesimpulan dan saran}

\section{V.1.Kesimpulan}

\section{A. Trotoar}

Dari analisa dan pembahasan diketahui bahwa kondisi trotoar disekitar Ruang terbuka Imam Bonjol sudah banyak yang rusak ,sehingga keselamatan dan keamanan pejalan kaki menjadi berkurang. Tidak adanya sarana bagi pejalan kaki difable dan ramp untuk 
pemakai kursi roda. Ditambah lagi dengan adanya keberadaan halte dari angkutan Trans Padang dan pos polisi yang berada diatas trotoar yang dapat menghambat pejalan kaki. B. Akses .

Dari aspek akses /jalan masuk menuju RTH Imambonjol banyak dan cukup memadai. Dari bagian depan (barat) mempunyai dua pintu masuk, tapi satu akses digunakan oleh area permainan anaka anak. Sisi utara hanya mempunyai satu pintu masuk dengan beberapa bagian pagar yang lepas. Sisi RTH bagian Timur mempunyai tiga pintu masuk. Sementara Sisi RTH Imambonjol sebelah selatan juga mempunyai tiga pintu masuk dan hampir tidak memiliki pagar sehingga dapat masuk dan mempunyai akses dari segala arah .

C. Parkir.

Area parkir disekitar RTH Imam Bonjol juga cukup memadai dengan area parkir bagian depan dan disekitar RTH Imam bonjol. Karena kawasan RTH Imambonjol terletak dipusat kota sehingga mempunyai jalan yang cukup lebar untuk digunakan sebagai tempat parkir roda 4 maupun roda 2.

\section{V.2. Saran.}

1.Harus ada perbaikan trotoar untuk menjamain kelancaran dan keamanan pejalan kaki dalam kondisi biasa maupun dalam kondisi darurat.

2. Memberikan fasilitas sirkulasi yang memadai bagi penyandang cacat atau difable.

3.Menjadikan RTH Imam Bonjol sebagai taman dengan tema taman evakuasi,sehingga masyarakat menjadi terbiasa dengan situasi darurat bencana gempa dan bencana lainya. 


\section{DAFTAR PUSTAKA.}

Berlin: Walter de Gnriter and Co. Shirvani, Hamid, 1985, The Urban Design Process, Van Nostrad Reinhold Company, New York.

Bell, Paul A, 1976.Environmental Psychology, W.B Sunders Company, Philadelpia

Boedojo, P dkk, 1986, Arsitektur,manusia dan pengamatanya, Djambatan, Jakarta

Carr, Stephen, Rivlin, Leaneg, Mark, Stone, Adre. M. 1992 Public Space,

Cambrige University Press. Rapoport, Amos, 1986, The Use And Design Of Open Space In

Urban Neighborhoods, dalam D.Frick (ads) The Quality of Urban Life.

Danisworo,N 1991 Teori Perancangan Urban Bandung ;ITB

Edward,Paul;THE ENCYCLOPEDIA OF PHILOSOPHY,vol 3\&4 Mac Millan Publishing Co Inc,1972,hal 308.

Forest Wilson : STRUKTUR ESENSI ARSITEKTUR, hal 15.

Haryadi B, Setyawan, 1995, Arsitektur Lingkungan dan Perilaku, Dirjen Dikti, Depdikbud, Jakarta

Hall,Edward, 1966, The Hidden Dimension, Doubleday and Company Inc,New York.

Lee E Koppelman, Joseph De Chiara, Time Saver Standar for site Planning

Lang,Jon,1987,Pengkajian Lingkungan Perilaku (terj),dalam Pengantar Arsitektur,Editor Snyder dan Catanesse,Erlangga,Jakarta.

Rahadi Fitra Anindya, Tesis Jalur pedestrian dikawasan Perdagangan dan jasa ditinjau dari aksesbilitas dan kenyamanan pengguna, Studi kasus jalan Sudirman kota Salatiga, 2003

Rapoport, Amos, 1977, Human Aspect Of Urban Form, Oxford: Pergamon Press

Rustam,Hakim,1987, Unsur Perancangan Dalam Arsitektur Landsekap, Bina Jakarta

Bandung

Rubenstein,Harvey,M,1987.Central City Malls,John Willey \& Son,New York. ,M,1992,Pedestrian Mall,Streetscapes and Urban Scapes, John Willey \& Son,New York.

Sarwono, Sarlito Wirawan, 1992 Psykologi Lingkungan, Grasindo PT.Gramedia

Widiasarana Indonesia, Jakarta

Spreiregen,Paul D,1986, Urban Architecture of Town and Cities.Mc Graw Hill Book Company,New York. 
SV Szokolay, ENVIRONMENTAL SCIENCE HAND BOOK: Lancoster: The Contruction Press 1980, )

Stroehle Johanes,desember 19 th 2008,How do pedestrian crowds react when they are in an emergency situation- models and software,University of Illinois at UrbanaChampaign.( jurnal)

Suryat,Toni Subrata, Tesis, Hubungan setting trotoar dengan tuntutan Atribut Pedagang Kaki lima, studi kasus Jln Prof H Soedarto SH Semarang, 2008 